\title{
REDUÇÃO DO TEMPO DE CORRIDA DO REFINO(TEMPO TAP TO TAP) SEM ADIÇÃO DE SUCATA *
}

\author{
Jose Antonio Miguel Rodrigues Junior ${ }^{1}$ \\ Manuel Enrique Rodriguez Blanc ${ }^{2}$ \\ Rogério Junji Arita ${ }^{3}$ \\ Bruno Cesar de Souza ${ }^{4}$ \\ Mario de Abreu Rodrigues 5 \\ Marco Aurelio Pedrosa dos Santos ${ }^{6}$ \\ Felipe Loureiro Pimentel ${ }^{7}$
}

\section{Resumo}

A média do tempo tap to tap para refino de uma corrida de ferroníquel era 280 minutos. O objetivo do projeto é alcançar média de 240 minutos. Realizado análise das principais perdas de tempo do processo de refino de ferroníquel, análise dos tempos e métodos do processo de amostragem de ferroníquel e brainstorming com os operadores. A partir destas informações foi realizada revisão na receita de refino de ferroníquel com a utilização de cálcio silício ao invés de alumínio para desoxidar a escória e teste com sensores de silício (sem utilização de CAPEX) e proposto para CAPEX utilização de espectrômetro de emissão atómica/óptica para reduzir tempo de espera por resultados de laboratório. A revisão da receita reduziu o tempo tap to tap de corridas sem sucata para 211 minutos.

Palavras-chave: Refino de ferro níquel; Tempo tap to tap.

\section{REDUCTION OF REFINERY CYCLE TIME (TAP TO TAP TIME) WITHOUT SCRAP ADDITION}

\section{Abstract}

The average of refining cycle time tap to tap of a ferronickel heat was 280 minutes. The target of the project is to achieve an average of 240 minutes. It was conducted analysis of the main time losses of the ferronickel refinery process, analysis of the times and methods of the ferronickel sampling process and brainstorming with the operators. After this information, a new instruction for modified technology were made for refining ferronickel using calcium silicon instead of aluminum to deoxidize the slag and test with Celox-Si sensors (without CAPEX) and proposed for CAPEX use optical spectrometer to reduce waiting time for laboratory chemical analysis. The new instruction reduced the time tap to tap of heats without scrap to 211 minutes.

Keywords: Ferro nickel refinery; Cycle time.

1 Engenheiro Metalurgista, Engenheiro, Gerente de Processo, Gerência de Desenvolvimento e Controle de Processo, Anglo American, Barro Alto, Goiás e Brasil.

2 Engenheiro Metalurgista, Engenheiro, Coordenador de Processo, Gerência de Desenvolvimento e Controle de Processo, Anglo American, Barro Alto, Goiás e Brasil.

3 Engenheiro Metalurgista, Engenheiro, Engenheiro de Processo, Gerência de Desenvolvimento e Controle de Processo, Anglo American, Barro Alto, Goiás e Brasil.

4 Técnico Metalurgista, Técnico, Técnico de Processo, Gerência de Desenvolvimento e Controle de Processo, Anglo American, Barro Alto, Goiás e Brasil.

5 Engenheiro Metalurgista, Engenheiro, Gerente de Produção, Anglo American, Barro Alto, Goiás e Brasil.

6 Engenheiro Químico, Engenheiro, Coordenador de Produção, Anglo American, Barro Alto, Goiás e Brasil.

7 Engenheiro Metalurgista, Engenheiro, Engenheiro de Produção, Anglo American, Barro Alto, Goiás e Brasil. 


\section{INTRODUÇÃO}

A produção de ferroníquel pela rota pirometalúrgica é ainda o método mais utilizado para o processamento de minérios lateríticos de níquel. O metal ferroníquel bruto vazado de um forno de redução possui composição química não adequada às condições de comercialização. A fim de refinar o metal bruto ("crude metal") obtido na operação de redução e também atingir as condições para granulação do metal, de forma a atender as exigências comerciais, tem-se o circuito da refinaria.

De forma geral, o refino de ferroníquel é conduzido de forma semelhante às condições de refino de aço baixo carbono. Entretanto, algumas peculiaridades devem ser tomadas em conta. A escolha do processo de refino e procedimentos mais adequados depende do estado do ferroníquel vazado do forno de redução. De forma a se obter um efetivo refino da liga FeNi com o menor custo possível e no menor tempo selecionou-se para a refinaria de Barro Alto Fornos Panelas e a operação de dessulfuração em meio reduzido (desoxidado).

O tempo tap to tap é tempo de ciclo para realizar a remoção dos elementos prejudiciais à qualidade da liga ferro-níquel, oriundos das operações anteriores, de forma a atender o padrão de comercialização estabelecido para o produto final. Elevado tempo tap to tap diminuem a produtividade da etapa de refino. O tempo media realizado eram 280 minutos, sendo a meta 240 min para corridas (bateladas) realizadas sem adição de sucata.

\section{MATERIAIS E MÉTODOS}

Em janeiro de 2016 iniciou-se o projeto $6 \sigma$ para redução do tempo de corrida do refino (tempo tap to tap) sem sucata.

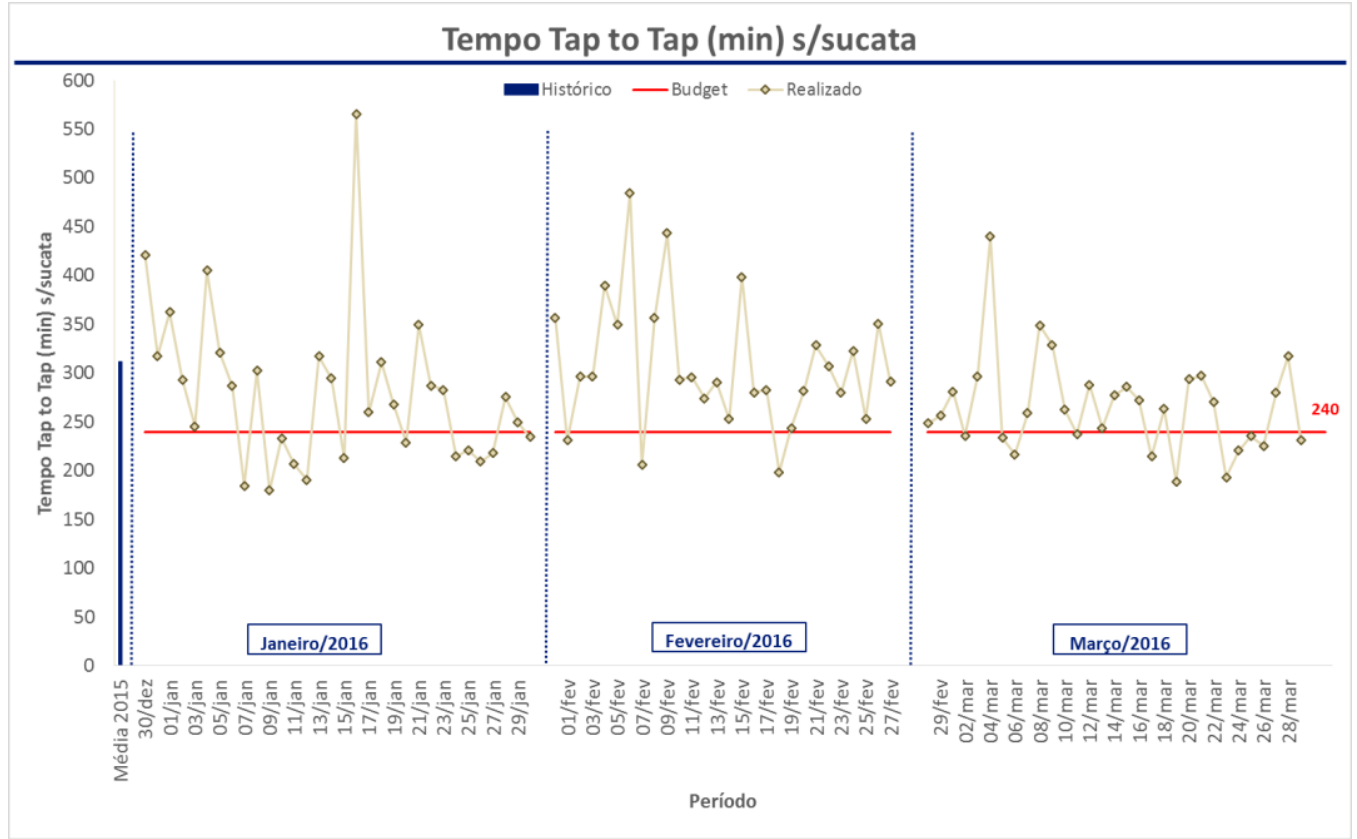

Figura 1. Gráfico de tempo tap to tap realizado 
Utilizando a metodologia DMAIC, foi levantado, priorizado e implementados ações para que o objetivo fosse atingido.

Entre as ações de maior relevância, foi à revisão da receita de refino da liga ferroníquel, que consiste na substituição do redutor da escória de Alumínio para Cálcio Silício e teste com CELOX Silício.

A utilização de ligas de cálcio, por exemplo, cálcio silício modifica as inclusões de alumina para cálcio-aluminatos de menor ponto de fusão e maior deformabilidade além de controlar a composição, a distribuição e a morfologia das inclusões remanescentes.

A modificação de inclusões de alumina sólida em cálcio-aluminatos líquidos (ou parcialmente líquidos) minimiza a ocorrência de "clogging" durante a granulação de metal.

Havia uma demora em se obter a análise química do metal refinado. Para trazer rapidez a essa etapa, foi realizado testes com a utilização de um sensor que mede o teor de silício no ferroníquel, o Celox Silício, com esta alternativa estaríamos explorando mais possibilidades que temos da instalação existente sem uso de investimento (Capex).

No mês de junho de 2016, a média do tempo tap to tap foi de 232 min, julho de 2016 a média do tempo tap to tap foi 231 minutos, agosto de 2016 a média do tempo tap to tap foi de 204 min e setembro de 2016 a média foi 211 minutos.

\section{RESULTADOS E DISCUSSÃO}

Utilizando a metodologia DMAIC, foi realizado levantamento de dados e análise dos dados para determinar quais ações seria necessário para reduzir o tempo tap to tap.

Realizado brainstorming com operadores e técnicos e foi levantado que os principais atrasos são devidos a corridas aguardarem analise química e corridas aguardando granulação de metal. Foram confrontadas estas informações utilizando gráficos de pareto.

O gráfico abaixo ilustra os atrasos das corridas. 


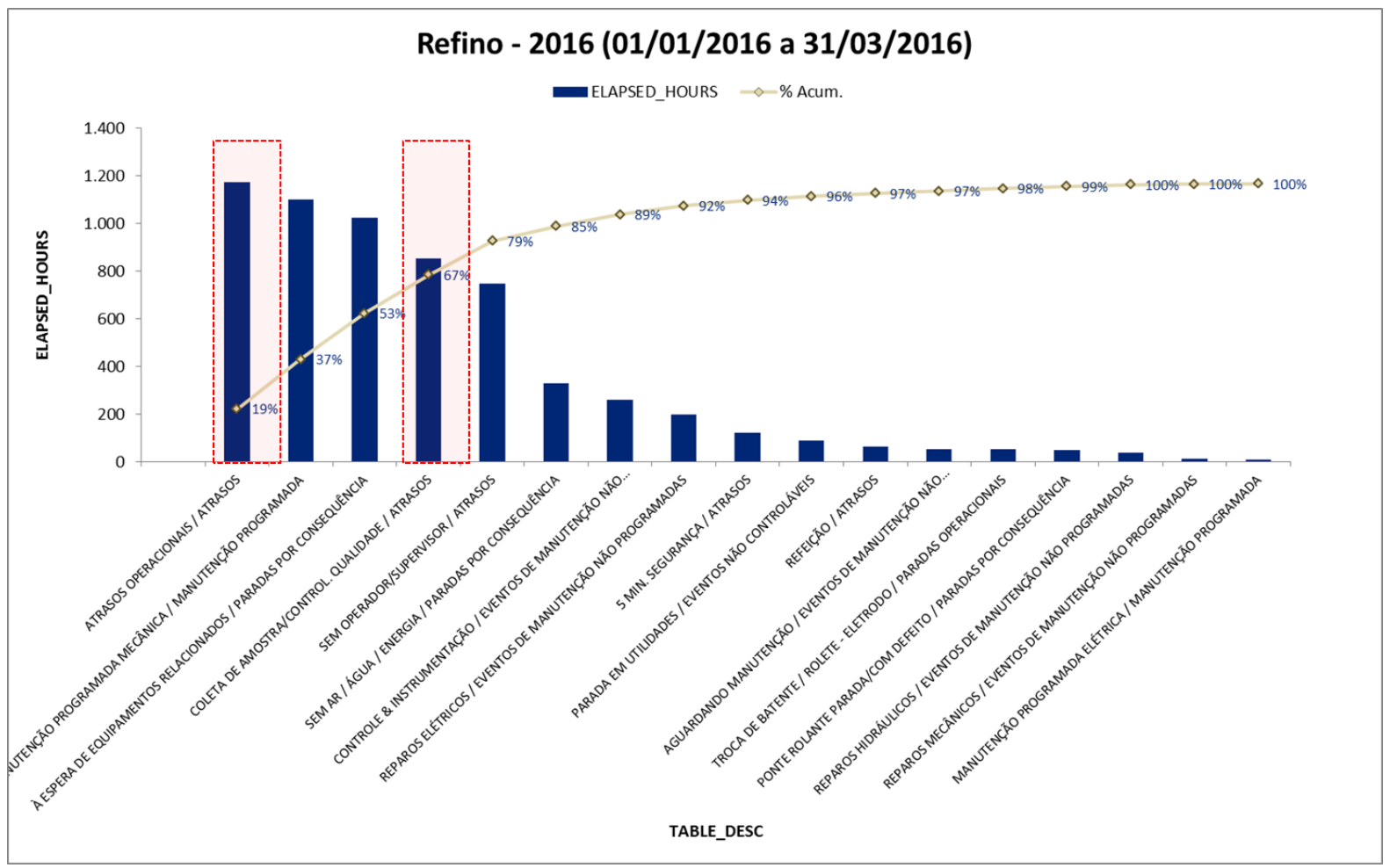

Figura 2. Gráfico de pareto dos atrasos

O gráfico abaixo ilustra os atrasos das corridas expandindo os atrasos operacionais.

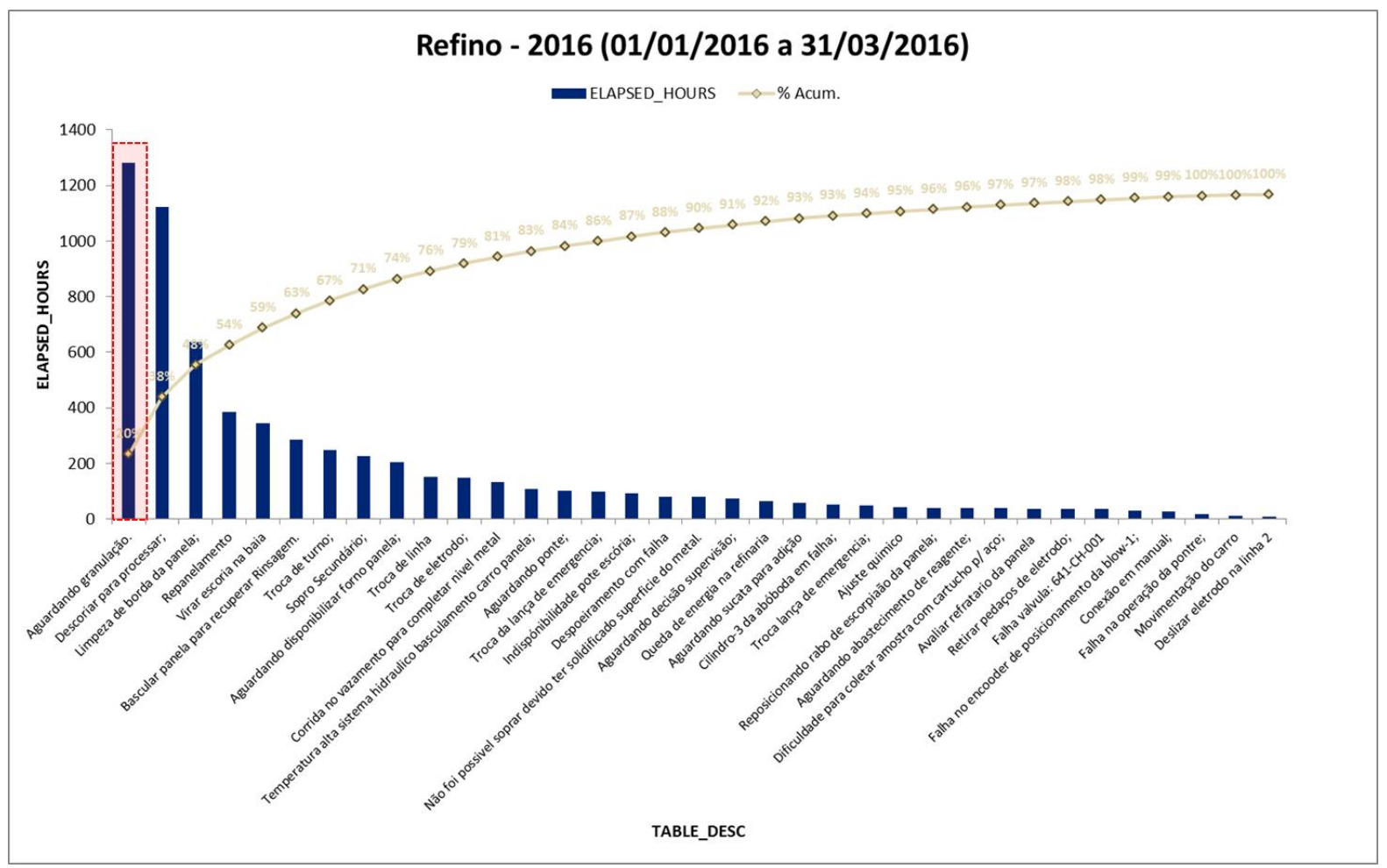

Figura 3. Gráfico de pareto dos atrasos expandido 

levantados.

Desta forma, metas específicas foram elaboradas para reduzir os atrasos

Para solucionar o atraso aguardando granulação, revisão da receita de refino de ferroníquel é necessário, já que estava ocorrendo entupimento do distribuidor e para reduzir o tempo de espera de resultado de amostra, foi acompanhado o processo de amostragem para determinar o qual etapa estava ocorrendo maior demora.

\subsection{Demora no resultado de análise química}

Durante o sopro de oxigênio para a redução no teor de carbono, silício e fósforo, o operador monitora além dos parâmetros do sopro a intensidade da reação. Desta forma, o sopro é finalizado somente quanto não for observado visualmente à reação. Após a etapa de sopro de oxigênio é realizado a remoção da escória oxidada.

A partir desta etapa, amostragem do metal é realizada e a etapa redutora do refino é iniciada.

Finalizada etapa redutora é realizado amostragem da escória e a partir da coloração é possível determinar se o metal foi dessulfurado e amostra do metal para análise química final é realizado e este resultado que impacta no tempo tap to tap.

O único elemento que não se tem nenhum parâmetro durante o processo é o silício, sendo assim, é o elemento que determina se a corrida está de acordo com as especificações.

A figura abaixo ilustra o processo de amostragem.

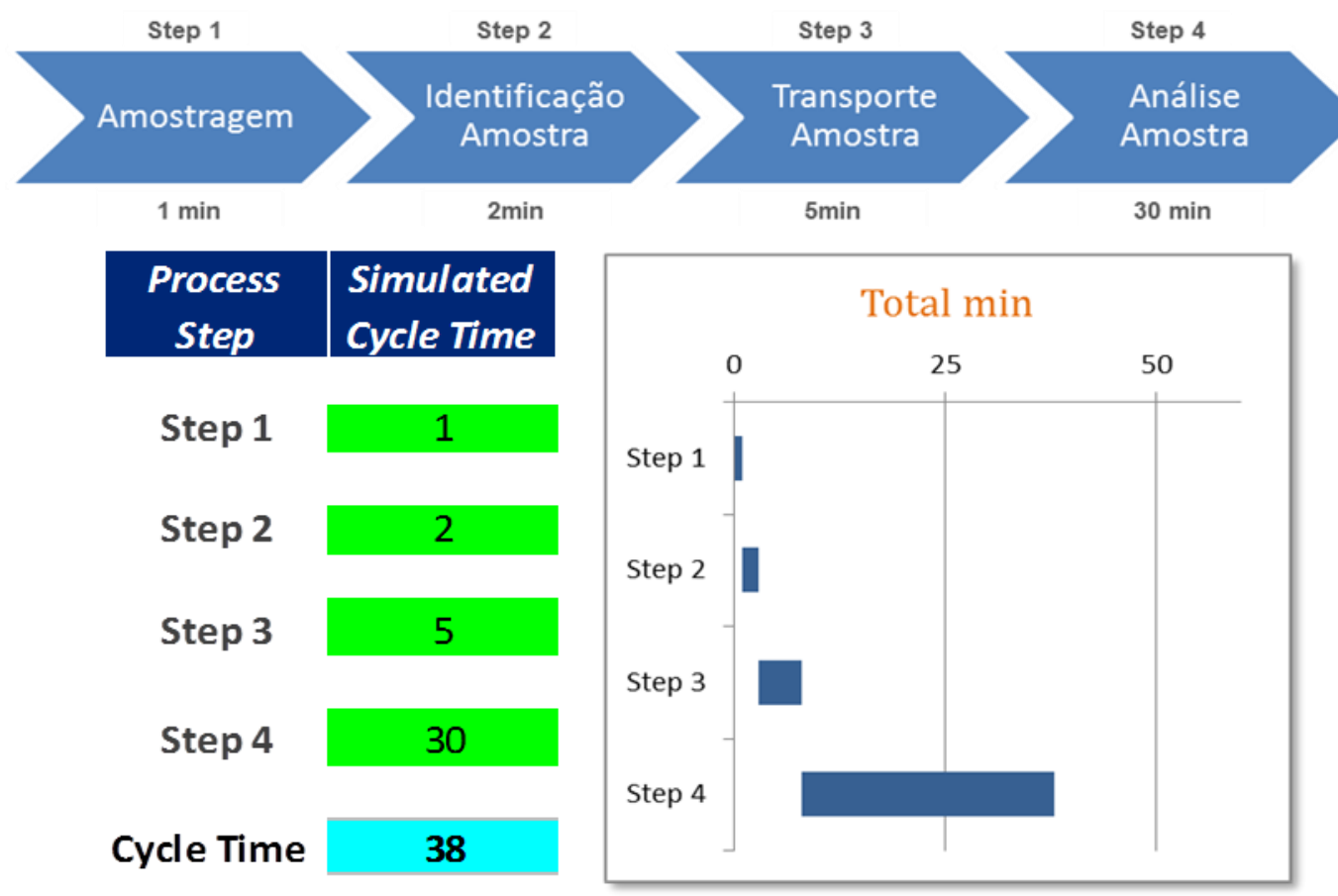

Figura 4. Processo de amostragem 
Com a finalidade de reduzir o tempo de espera de resultado de amostra, teste com CELOX Silício foi realizado como ação imediata sem utilização de CAPEX, conforme resultados abaixo.

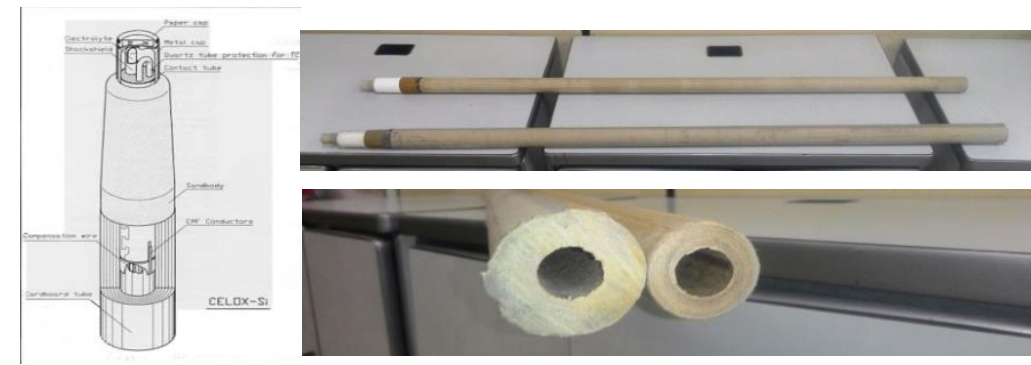

Figura 5. Sensor Celox Silicio

Tabela 1. Resultados teste Celox Silício

\begin{tabular}{|r|c|c|}
\hline $\mathbf{\#}$ & \%Si Celox & \%Si Lab. RX \\
\hline $\mathbf{1}$ & 0,061 & 0,066 \\
\hline $\mathbf{2}$ & 0,107 & 0,066 \\
\hline $\mathbf{3}$ & 0,061 & 0,087 \\
\hline $\mathbf{4}$ & 0,281 & 0,228 \\
\hline $\mathbf{5}$ & 0,284 & 0,228 \\
\hline $\mathbf{6}$ & 0,273 & 0,339 \\
\hline $\mathbf{7}$ & 0,282 & 0,308 \\
\hline $\mathbf{8}$ & 0,275 & 0,278 \\
\hline $\mathbf{9}$ & 0,273 & 0,220 \\
\hline $\mathbf{1 0}$ & 0,274 & 0,220 \\
\hline $\mathbf{1 1}$ & 0,290 & 0,248 \\
\hline $\mathbf{1 2}$ & 0,275 & 0,116 \\
\hline $\mathbf{1 3}$ & 0,290 & 0,180 \\
\hline $\mathbf{1 4}$ & 0,272 & 0,294 \\
\hline $\mathbf{1 5}$ & 0,293 & 0,206 \\
\hline $\mathbf{1 6}$ & 0,295 & 0,082 \\
\hline $\mathbf{1 7}$ & 0,271 & 0,323 \\
\hline
\end{tabular}

A solução ideal para reduzir a meta de tempo tap to tap de 240 minutos para 210 minutos foi à aquisição de espectrômetro de emissão atómica/óptica, utilizando CAPEX em 2014.

Este equipamento é utilizado em operações semelhantes a nossa e possibilitará maior flexibilidade a operação do refino, já que não necessitará levar amostra ao laboratório e aguardar analise para tomada de decisão, além de reduzir custos de energia elétrica, nitrogênio, materiais refratários e eletrodos.

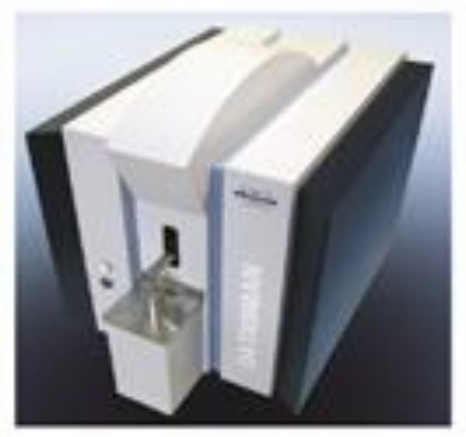

Figura 6. Espectrômetro de emissão atómica/óptica 
Os benefícios associados a utilização do espectrômetro de emissão atómica/óptica são:

- Aumento da produtividade, Redução do tempo tap to tap para 210 minutos, possibilitando 13,7 corridas por dia.

- Flexibilidade da operação, Disponibilidade para fusão de sucata.

- Disponibilidade dos equipamentos, aumento na disponibilidade dos equipamentos para manutenção preventiva/inspeção.

- Custos, Saving no consumo energia elétrica na ordem de $\mathrm{R} \$ 309.849,00$ por mês.

\subsection{Revisão da receita de refino de ferroníquel}

Durante a etapa de refino de $\mathrm{FeNi}$, se faz necessário a adição de agente desoxidante de escória, condição para permitir a dessulfuração do metal. O alumínio granulado era utilizado nesta etapa do processo. Para reduzir o tempo tap to tap foi realizado revisão da receita para utilização de CaSi $0,1-1,0 \mathrm{~mm}$ para desoxidação da escória e elemento dessulfurante.

A adição de CaSi era realizada de forma manual da mesma forma que o alumínio, no entanto devido a sua granulometria parte era succionado pelo sistema de despoeiramento. Para solucionar a perda deste insumo e eliminar a condição de adição manual, esta iniciativa visa a utilização de CaSi 7,0-20,0 mm em substituição do alumínio granulado.

$\mathrm{Na}$ receita nova, a quantidade de fluorita e $\mathrm{MgO}$ adicionada foi aumentada em relação a receita original com a finalidade de reduzir tempo tap to tap.

O gráfico abaixo mostra a evolução do tempo tap to tap antes e após a implementação da receita.
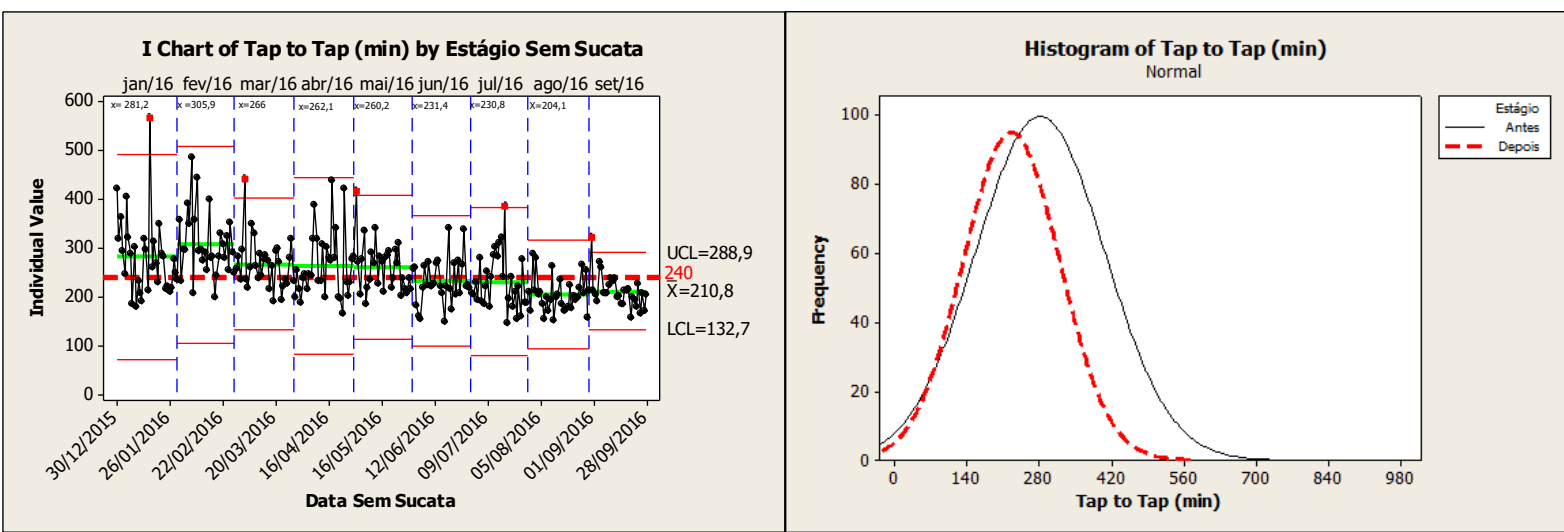

Figura 7. Evolução tempo tap to tap

O gráfico abaixo mostra a redução do \% alumínio antes e após a implementação da receita. 


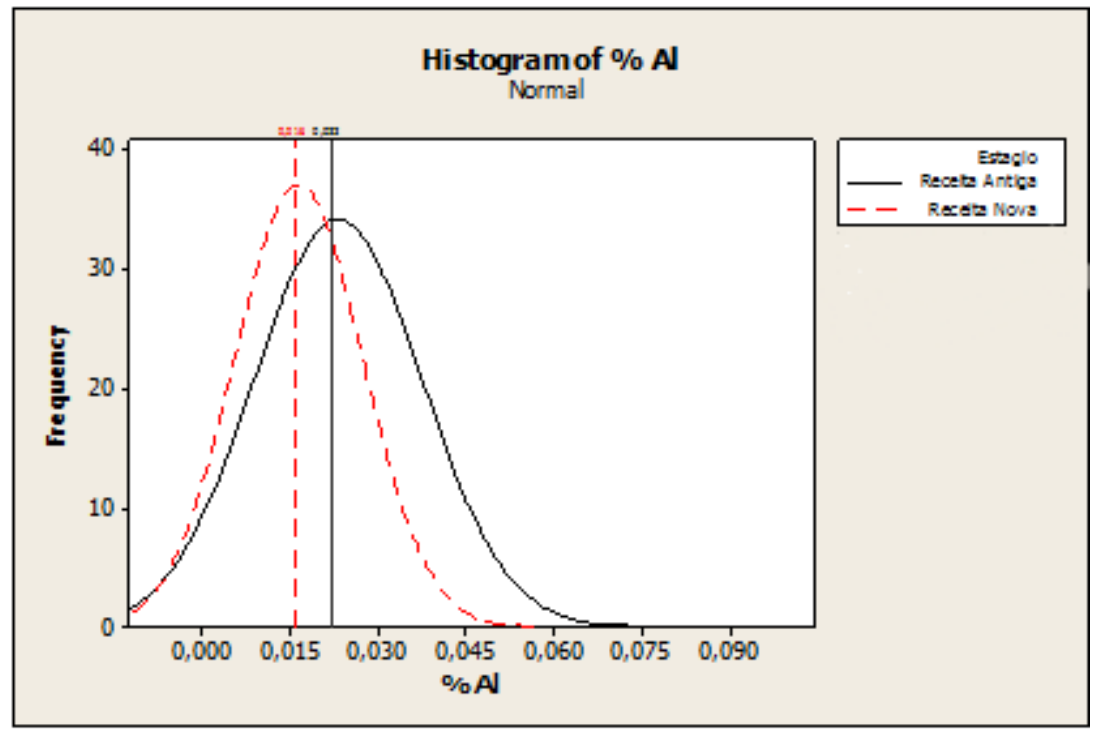

Figura 8. Redução do teor de alumínio elétrica.

A tabela abaixo ilustra a evolução dos ganhos no tempo tap to tap e energia

Tabela 2. Ganhos calculados

\begin{tabular}{|c|c|c|c|c|c|c|c|c|c|c|}
\hline & & jan/16 & fev/16 & $\mathrm{mar} / 16$ & $a b r / 16$ & mai/16 & jun/16 & $\mathrm{jul} / 16$ & ago/16 & set/16 \\
\hline \multirow{8}{*}{ Actual ( base real) } & Actual & 281 & 306 & 266 & 262 & 263 & 232 & 231 & 204 & 211 \\
\hline & Preço & 209,72 & 207,51 & 195,48 & 196,69 & 199,17 & 196,65 & 160,43 & 167,38 & 165,60 \\
\hline & Kwh/min & 36,45 & 36,71 & 39,02 & 38 & 40,64 & 42,12 & 41,07 & 42,43 & 42,45 \\
\hline & Baseline & 2.148 .046 & 2.331 .032 & 2.028 .926 & 1.958 .203 & 2.128 .828 & 1.921 .608 & 1.521 .987 & 1.448 .794 & 1.483 .271 \\
\hline & Diferença & 123.216 & 306.202 & 4.096 & 66.627 & 103.998 & 103.222 & 502.843 & 576.036 & 541.559 \\
\hline & & & & 1 & 1 & & 1 & & , & \\
\hline & & & & & & & & & & \\
\hline & & Def & & Measure & Analyse & Imp & ove & Co & rol & \\
\hline
\end{tabular}

\subsection{Ganhos segurança do trabalho}

Com a utilização do cálcio silício $7-20 \mathrm{~mm}$ houve redução dos riscos envolvendo a operação conforme matriz $5 \times 5$. 


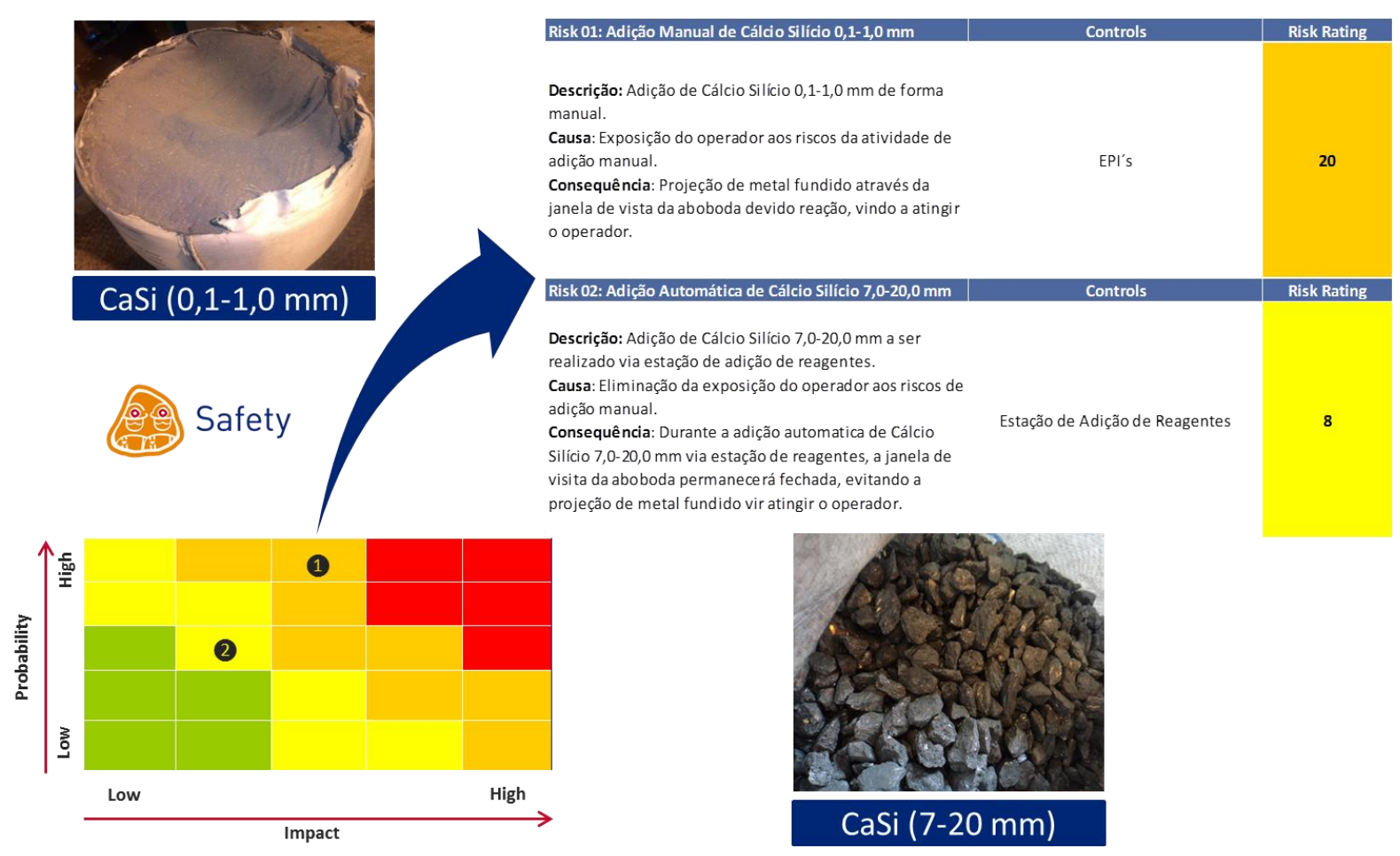

Figura 9. Redução do risco de segurança do trabalho

Na revisão da receita, a adição de fluorita foi alterada de adição manual para via estação de reagente, reduzindo risco analogamente ao CaSi.

\section{CONCLUSÃO}

Conforme os levantamentos realizados e ações implementadas durante o projeto, foi possível reduzir o tempo tap to tap para a meta estabelecida.

A revisão da receita permitiu a redução do tempo tap to tap, solucionou o problema de entupimento de distribuidor na granulação de metal e diminuiu a exposição dos riscos operacionais.

Após a conclusão do projeto, para reduzir o tempo tap to tap para 210 minutos, se faz necessário a utilização de CAPEX. Essa redução implicará numa diminuição no consumo de energia elétrica.

\section{REFERÊNCIAS}

1 Christian Red, Matthias Pfennig, Roland Krist, Siegfried Fritsch, Heinz Muller. Refining of ferronickel. The thirteenth International Ferroalloys Congress (Efficient technologies in ferroalloy industry). 2013. Páginas 229 a 236 